\title{
Effect of Ingredients on the Bacteriological Profile of Ready to Eat Meat Sandwiches
}

\section{Mohamed A. Hussein*, Samar H. Mohamed, Ahmed E. Tharwat, Abd El-Salam E. Hafez, REHAM A. GoMAa}

Food Control Department, Faculty of Veterinary Medicine, Zagazig University, Zagazig 44519, Egypt.

\begin{abstract}
The current study aimed to investigate the bacteriological quality of the ready-to-eat (RTE) meat sandwiches prepared using the meat and treated ingredients viz., green salad and tahini sauce. Two hundred and forty samples of RTE meat sandwiches, vegetable salad, and tahini sauce were used in the study. The washing of vegetable salad for 10 min with water providing $50 \mathrm{ppm}$ chlorine reduced $(p<0.05)$ the aerobic plate count (APC), Bacillus cereus (B. cereus) and Staphylococcus aureus (S. aureus) count. Similarly, addition of $1 \%$ garlic essential oil during formulation of tahini sauce reduced $(p<0.05)$ APC, B. cereus and S. aureus count. The counts in RTE meat sandwiches after using treated green salad and tahini sauce reduced $(p<0.05)$ APC count from $(5.58 \pm 1.21$ and $6.54 \pm 1.12)$ to $(3.2 \pm 0.22$ and $4.89 \pm 0.31) \log _{10} \mathrm{CFU} / \mathrm{g}$. The counts of B.cereus reduced $(p<0.05)$ from $(2.98 \pm 0.11$ and $3.34 \pm 0.15)$ to $(<2$ and $2.49 \pm 0.09)$ and S.aureus reduced $(p<0.05)$ from $(3.18 \pm 0.15$ and $3.85 \pm 0.13)$ to $(<2$ and $2.87 \pm 0.09) \log _{10} \mathrm{CFU} / \mathrm{g}$. These results demonstrated that use of treated vegetable salad (washed by chlorine water) and tahini sauce (containing $1 \%$ garlic essential oil) in preparation of RTE meat sandwiches results the improved bacteriological quality of RTE meat sandwiches.
\end{abstract}

Keywords | Staphylococcus aureus, Bacillus cereus, meat sandwiches, garlic oil, chlorine, Burger, sausage.

Received | July 21, 2021; Accepted | August 08, 2021; Published | August 25, 2021

*Correspondence | Mohamed A. Hussein, Food Control Department, Faculty of Veterinary Medicine, Zagazig University, Zagazig 44519, Egypt; Email: elged2010@yahoo.com

Citation | Hussein MA, Samar HM, Tharwat AE, Hafez AE, Gomaa RA (2021). Effect of ingredients on the bacteriological profile of ready to eat meat sandwiches. J. Anim. Health Prod. 9(s1): 69-75.

DOI | http://dx.doi.org/10.17582/journal.jahp/2021/9.s1.69.75

ISSN | 2308-2801

Copyright (C) 2021 Hussein et al. This is an open access article distributed under the Creative Commons Attribution License, which permits unrestricted use, distribution, and reproduction in any medium, provided the original work is properly cited.

\section{INTRODUC'TION}

$\mathrm{T}$ he consumption of ready to eat (RTE) food has been associated with serious health problems of consumers all over the world (FDA, 2000). The incidence of foodborne illness globally increased, this may in part be attributed to a minimal heat treatment used in RTE food production as well as using of some seasoning such as vegetable salads and tahini sauce, which not subjected to heat treatment (Hussein et al., 2018). The aerobic plate count (APC) is an important factor for predication of microbial quality evaluation in food products and is an indicator of microbial contamination level in food production (Kim et al, 2018). Staphylococcus aureus origin food-borne illness reported as the third most important cause of disease in the world (Zhang et al., 1998). In United States, a few decades ago, $S$. aureus was responsible for $25 \%$ of all food-borne illnesses (Tamarapu et al., 2001). Presence of Bacillus cereus organisms is common in meat products, and due to their resistant endospores they may survive different treatments during food production. B.cereus counts in excess of $10^{5}$ $10^{6} \mathrm{~g}$ have been encountered in food supposed of causing illness (Griffiths and Schraft, 2017). Nowadays, RTE meat products are the important part of the diet so the contamination and multiplication of B. cereus in RTE sandwiches is of concern as public health hazard. B. cereus is commonly associated with toxico-infection, as it induces both diarrheal and emetic types of food borne illness. Out of two, diarrheal type illness caused by enterotoxin (s), results in diarrhea, and the emetic type induces vomiting and nausea. 
Sometimes both types of symptoms are appeared probably due to the synergistic actions of one or more enterotoxin(s) (Jessberger et al., 2020).

The unsatisfactory microbiological quality of served RTE sandwiches considered as a big question facing the researchers and food inspection authorities in Egypt. After heat treatment of meat products, the addition of vegetable salad and tahini sauce, which not previously heated this, constitutes a biological hazard necessities marking with a critical control point. Washing fresh vegetables in chlorinated water $(50-200 \mathrm{mg} / \mathrm{L}$ of active chlorine) reduce the levels of bacteria. Sodium hypochlorite is the most commonly used sanitizer in the fresh-cut industry (Lee and Baek, 2008). Garlic, a member of Alliaceae family has a high pungent flavor that improved with cooking. It has been used to combat infections such as cough, cold, diarrhea, asthma, flu, headache, sore throat, abdominal discomfort and respiratory tract infections (Chand, 2013).

The aim of this work is to improve the hygienic status and safety of the ready-to-eat sandwiches through improving the preparation steps of the green salad and tahini sauce. Thus, we aimed to explore the effects of chlorine water washing on vegetable salad and addition of garlic essential oil in tahini sauce, and ultimate effect of addition of these treated ingredients on the microbiological quality of RTE meat sandwiches.

\section{MATERIALS AND METHODS}

Two hundred and forty samples of ready to eat meat sandwiches, vegetable salad, and tahini sauce were collected from a restaurant at Zagazig city, Egypt.

The work plane classified into four groups:

Group 1: Seventy samples ready to eat meat sandwich (liver, beef burger, sausage, shawarma, and kofta), vegetable salad, and tahini sauce (10 of each). The sandwiches composed of main meat product with tahini sauce and vegetable salad without any modification.

Group 2: The contents of vegetable salad (Solanum lycopersicum, Cucumis sativus, Lactuca sativa, Capsicum annuum, Coriandrum sativum and Eruca sativa) were washed in for 10 minutes in sodium hypochlorite solution that provide $50 \mathrm{ppm}$ chlorine. Then the vegetable cautiously cut and mixed and kept in a fridge at $4^{\circ} \mathrm{C}$ for two hours and used in sandwich preparation. Sixty samples obtained from ready to eat meat sandwich (liver, beef burger, sausage, shawarma, kofta) and vegetable salad (10 of each). The sandwiches obtained after using of treated vegetable salads and no treatment in tahini sauce.
Group 3: The contents of tahini sauce (ground sesame seeds, lemon juice, garlic, and water) were heated at $80{ }^{\circ} \mathrm{C}$ for 3 minutes followed by rapid cooling with addition of $1 \% \mathrm{wt}$. volume garlic essential oil, then kept in a fridge at $4^{\circ} \mathrm{C}$ kept for two hours and used in sandwich preparation. Sixty samples obtained from ready to eat meat sandwich (liver, beef burger, sausage, shawarma, kofta) and tahini sauce (10 of each). The sandwiches obtained after using of treated tahini sauce and no treatment in vegetable salad.

Group 4: Fifty samples of ready to eat meat sandwich liver, beef burger, sausage, shawarma, kofta (10 of each), obtained after using of treated of vegetable salads and treated tahini sauce.

The samples were prepared according to ISO 6887-2: (2003). Twenty five grams of each sandwiches core were homogenized aseptically for $1 \mathrm{~min}$ with $225 \mathrm{ml}$ of $0.1 \%$ peptone water in a stomacher (Colworth, 400) then serially diluted to 10 -fold in the same diluent.

Enumeration of APC was done according to ISO 4833-1: (2013) using plate count agar (Oxoid, CM325). Bacillus cereus count was performed according to ISO 7932:(2004) using $B$. cereus selective agar base with egg yolk and polymyxin supplement media. B.cereus identified morphologically and biochemically according to Cowan and steel (1974). The S. aureus count was applied according to ISO 6888-1:(1999) using Baird Parker (BP) agar (Oxoid, CM275), supplemented with egg yolk tellurite emulsion $\left(50 \mathrm{~m} / \mathrm{L}\right.$, Oxoid SR54) and incubated at $37^{\circ} \mathrm{C}$ for $24-48$ hrs.

\section{Statistical Analysis}

The obtained results were statistically evaluated by the application of Analysis of Variance (ANOVA) test according to Feldman et al. (2003).

\section{RESULTS}

\section{Aerobic plate Count (APC)}

The APC in retail liver sandwich, beef burger sandwich, sausage sandwich, shawarma sandwich, kofta sandwich, vegetable salad and tahini sauce were $5.58 \pm 1.21,6.13 \pm$ $0.92,6.18 \pm 0.92,6.27 \pm 1.02,6.54 \pm 1.12,7.32 \pm 1.29$ and $8.04 \pm 1.12 \log _{10} \mathrm{CFU} / \mathrm{g}$, respectively (group 1) (Table 1). After replacing of ordinary vegetable salad with that prepared by washing all ingredient in chlorinated water $(50 \mathrm{ppm})$ the counts reduced to $5.11 \pm 0.31,5.64 \pm 0.26$, $5.81 \pm 0.17,5.02 \pm 0.19,5.68 \pm 0.31$ and $4.26 \pm 0.41$ log${ }_{10} \mathrm{CFU} / \mathrm{g}$, in liver sandwich, beef burger sandwich, sausage sandwich, shawarma sandwich, kofta sandwich and vegetable salad, respectively (group 2). Meanwhile, using of modified tahini sauce contained garlic essential oil reduce 
Table 1: Aerobic plate count $\log _{10} \mathrm{CFU} / \mathrm{g}(\mathrm{Mean} \pm \mathrm{SD})$ of ready to eat meat sandwiches, vegetable salad and tahini sauce.

\begin{tabular}{lllll} 
Samples & Group 1 & Group 2 & Group 3 & Group 4 \\
Liver sandwiches & $5.58 \pm 1.21^{\mathrm{a}}$ & $5.11 \pm 0.31^{\mathrm{a}}$ & $5.17 \pm 0.29^{\mathrm{a}}$ & $3.2 \pm 0.22^{\mathrm{c}}$ \\
\hline Beef burger sandwiches & $6.13 \pm 0.92^{\mathrm{a}}$ & $5.64 \pm 0.26^{\mathrm{b}}$ & $5.74 \pm 0.26^{\mathrm{ab}}$ & $4.32 \pm 0.31^{\mathrm{c}}$ \\
\hline Sausage sandwiches & $6.18 \pm 0.92^{\mathrm{a}}$ & $5.81 \pm 0.17^{\mathrm{b}}$ & $5.91 \pm 0.34^{\mathrm{a}}$ & $4.13 \pm 0.32^{\mathrm{c}}$ \\
Shawarma sandwiches & $6.27 \pm 1.02^{\mathrm{a}}$ & $5.02 \pm 0.19^{\mathrm{b}}$ & $5.38 \pm 0.23^{\mathrm{b}}$ & $3.9 \pm 0.19^{\mathrm{c}}$ \\
Kofta sandwiches & $6.54 \pm 1.12^{\mathrm{a}}$ & $5.68 \pm 0.31^{\mathrm{b}}$ & $5.81 \pm 0.31^{\mathrm{b}}$ & $4.89 \pm 0.31^{\mathrm{c}}$ \\
Vegetable salad & $7.32 \pm 1.29^{\mathrm{a}}$ & $4.26 \pm 0.41^{\mathrm{b}}$ & - & - \\
Tahini sauce & $8.04 \pm 1.12^{\mathrm{a}}$ & - & $3.98 \pm 0.36^{\mathrm{b}}$ & -
\end{tabular}

The values given above are means of replicate values ( $\mathrm{n}=10$ for each group)

Within rows, means with different superscript small letters are statistically significant $(p<0.05)$.

Group 1: No treatment, group 2: added treated vegetable salad, group3: added treated tahini sauce, group 4: added treated vegetable salad and tahini sauce.

Table 2: Bacillus cereus $\log _{10} \mathrm{CFU} / \mathrm{g}$ (Mean $\pm \mathrm{SD}$ ) of ready to eat meat sandwiches, vegetable salad and tahini sauce.

\begin{tabular}{lllll} 
Sandwiches & Group 1 & Group 2 & Group 3 & Group 4 \\
Liver sandwiches & $3.26 \pm 0.13^{\mathrm{a}}$ & $2.78 \pm 0.13^{\mathrm{ab}}$ & $2.42 \pm 0.15^{\mathrm{b}}$ & $<2^{\mathrm{c}}$ \\
Beef burger sandwiches & $3.34 \pm 0.15^{\mathrm{a}}$ & $2.84 \pm 0.11^{\mathrm{ab}}$ & $2.27 \pm 0.14^{\mathrm{b}}$ & $2.31 \pm 0.13^{\mathrm{b}}$ \\
Sausage sandwiches & $2.98 \pm 0.11^{\mathrm{a}}$ & $2.79 \pm 0.11^{\mathrm{a}}$ & $2.14 \pm 0.09^{\mathrm{b}}$ & $<2^{\mathrm{c}}$ \\
\hline Shawarma sandwiches & $3.11 \pm 0.13^{\mathrm{a}}$ & $2.81 \pm 0.13^{\mathrm{a}}$ & $2.34 \pm 0.12^{\mathrm{b}}$ & $<2^{\mathrm{c}}$ \\
Kofta sandwiches & $3.23 \pm 0.22^{\mathrm{a}}$ & $2.98 \pm 0.11^{\mathrm{ab}}$ & $2.85 \pm 0.14^{\mathrm{b}}$ & $2.49 \pm 0.09^{\mathrm{c}}$ \\
Vegetable salad & $4.11 \pm 0.19^{\mathrm{a}}$ & $<2^{\mathrm{b}}$ & - & - \\
Tahini sauce & $4.92 \pm 0.26^{\mathrm{a}}$ & - & $<2^{\mathrm{b}}$ & -
\end{tabular}

The values given above are means of replicate values ( $\mathrm{n}=10$ for each group)

Within rows, means with different superscript small letters are statistically significant $(p<0.05)$.

Group 1: No treatment, group 2: added treated vegetable salad, group3: added treated tahini sauce, group 4: added treated vegetable salad and tahini sauce.

Table 3: Staphylococcus aureus $\log _{10} \mathrm{CFU} / \mathrm{g}$ (Mean $\pm \mathrm{SD}$ ) of ready to eat meat sandwiches, vegetable salads and tahini sauce.

\begin{tabular}{|c|c|c|c|c|c|}
\hline Sandwiches & \multicolumn{2}{|c|}{ Group 1} & Group 2 & Group 3 & Group 4 \\
\hline Liver sandwiches & \multicolumn{2}{|c|}{$3.18 \pm 0.15^{\mathrm{a}}$} & $2.34 \pm 0.14^{b}$ & $2.38 \pm 0.17^{\mathrm{b}}$ & $<2^{c}$ \\
\hline Beef burger sandwiches & \multicolumn{2}{|c|}{$3.74 \pm 0.11^{\mathrm{a}}$} & $3.39 \pm 0.12^{\mathrm{ab}}$ & $2.49 \pm 0.15^{b}$ & $2.87 \pm 0.18^{b}$ \\
\hline Sausage sandwiches & \multicolumn{2}{|c|}{$3.42 \pm 0.17^{\mathrm{a}}$} & $2.91 \pm 0.11^{\mathrm{b}}$ & $2.82 \pm 0.13^{b}$ & $2.3 \pm 0.15^{\mathrm{c}}$ \\
\hline Shawarma sandwiches & \multicolumn{2}{|c|}{$3.85 \pm 0.13^{\mathrm{a}}$} & $2.83 \pm 0.09^{b}$ & $2.75 \pm 0.11^{\mathrm{b}}$ & $<2^{c}$ \\
\hline Kofta sandwiches & \multicolumn{2}{|c|}{$3.65 \pm 0.18^{\mathrm{a}}$} & $3.45 \pm 0.16^{\mathrm{ab}}$ & $2.48 \pm 0.12^{\mathrm{b}}$ & $2.34 \pm 0.17^{b}$ \\
\hline Vegetable salad & \multicolumn{2}{|c|}{$4.11 \pm 0.19^{\mathrm{a}}$} & $<2^{\mathrm{b}}$ & - & - \\
\hline \multicolumn{6}{|c|}{$\begin{array}{l}\text { The values given above are means of replicate values ( } \mathrm{n}=10 \text { for each group) } \\
\text { Within rows, means with different superscript small letters are statistically significant }(\mathrm{p}<0.05) \text {. } \\
\text { Group 1: No treatment, group 2: added treated vegetable salad, group3: added treated tahini sauce, group 4: added treated vegetable } \\
\text { salad and tahini sauce. }\end{array}$} \\
\hline \multicolumn{2}{|c|}{$\begin{array}{l}\text { the counts to } 5.17 \pm 0.29,5.74 \pm 0.26,5.91 \pm 0.34,5.38 \pm \\
0.23,5.81 \pm 0.31,3.98 \pm 0.36 \log _{10} \mathrm{CFU} / \mathrm{g} \text {, in liver sand- } \\
\text { wich, beef burger sandwich, sausage sandwich, shawarma } \\
\text { sandwich, kofta sandwich and tahini sauce, respectively } \\
\text { (group } 3 \text { ). Significant reductions in APC count in all sand- } \\
\text { wiches ( } p<0.05 \text { ) after using of treated vegetable salad and } \\
\text { tahini sauce (group 4). }\end{array}$} & \multicolumn{4}{|c|}{$\begin{array}{l}\text { BACILLUS CEREUS COUNT } \\
\text { The presented data in Figure } 1 \mathrm{~A} \text { and Table } 2 \text { showed the } \\
\text { percentage incidence and CFU counts of B. cereus in sand- } \\
\text { wiches i.e., } 50 \%(3.26 \pm 0.13), 60 \%(3.34 \pm 0.15), 70 \% \\
(2.98 \pm 0.11), 70 \%(3.11 \pm 0.13) \text { and } 80 \%(3.23 \pm 0.22) \text {, } \\
\text { respectively in liver sandwich, beef burger sandwich, sau- } \\
\text { sage sandwich, shawarma sandwich, and kofta sandwich } \\
\text { (in group 1). The incidence and count of B.cereus was re- }\end{array}$} \\
\hline
\end{tabular}


duced after treatment of salad (in group 2) to $30 \%$ (2.78 $\pm 0.13), 60 \%$ (2.84 \pm 0.11$), 50 \%$ (2.79 \pm 0.11$), 60 \%$ (2.81 $\pm 0.13)$ and $70 \%(2.98 \pm 0.11) \log _{10} \mathrm{CFU} / \mathrm{g}$. Meanwhile, it became $20 \%(2.42 \pm 0.15), 40 \%$ (2.27 \pm 0.14$), 20 \%$ (2.14 \pm $0.09), 40 \%(2.34 \pm 0.12)$ and $40 \%(2.85 \pm 0.14) \log _{10} \mathrm{CFU} / \mathrm{g}$ in liver sandwich, beef burger sandwich, sausage sandwich, shawarma sandwich, and kofta sandwiches, respectively (in group 3) tahini sauce treated. Moreover, both treatments of vegetable salad and tahini sauce reduced B.cereus incidence to undetectable levels in liver sandwich, sausage sandwich, and shawarma sandwich (group 4).

\section{STAPHYLOCOCCUS AUREUS COUNT}

The presented data in Figure 1B and Table 3 showed the percentage incidence and CFU counts of S.aureus in sandwiches. It showed counts of $60 \%(3.18 \pm 0.15), 70 \%$ (3.74 \pm $0.11), 60 \%(3.42 \pm 0.17), 70 \%(3.85 \pm 0.13)$ and $70 \%(3.65$ \pm 0.18 ), respectively in liver, beef burger, sausage, shawarma and kofta in (group1). The incidence and count of S.aureus was reduced after treatment of salad (group2) to 30\% (2.34 \pm 0.14$), 40 \%$ (3.39 \pm 0.12$), 30 \%$ (2.91 \pm 0.11$), 30 \%$ $(2.83 \pm 0.09)$ and $40 \%(3.45 \pm 0.16) \log _{10}$ CFU/g. Meanwhile, it became $50 \%(2.38 \pm 0.17), 70 \%(2.49 \pm 0.15), 40 \%$ $(2.82 \pm 0.13), 60 \%(2.75 \pm 0.11)$ and $70 \%(2.48 \pm 0.12)$ $\log _{10} \mathrm{CFU} / \mathrm{g}$ in liver sandwich, beef burger sandwich, sausage sandwich, shawarma sandwich and kofta sandwich, respectively in tahini sauce treated group (group 3). Moreover, both treatments of vegetable salad and tahini sauce reduced S.aureus incidence to undetectable levels in liver and sausage (group 4).
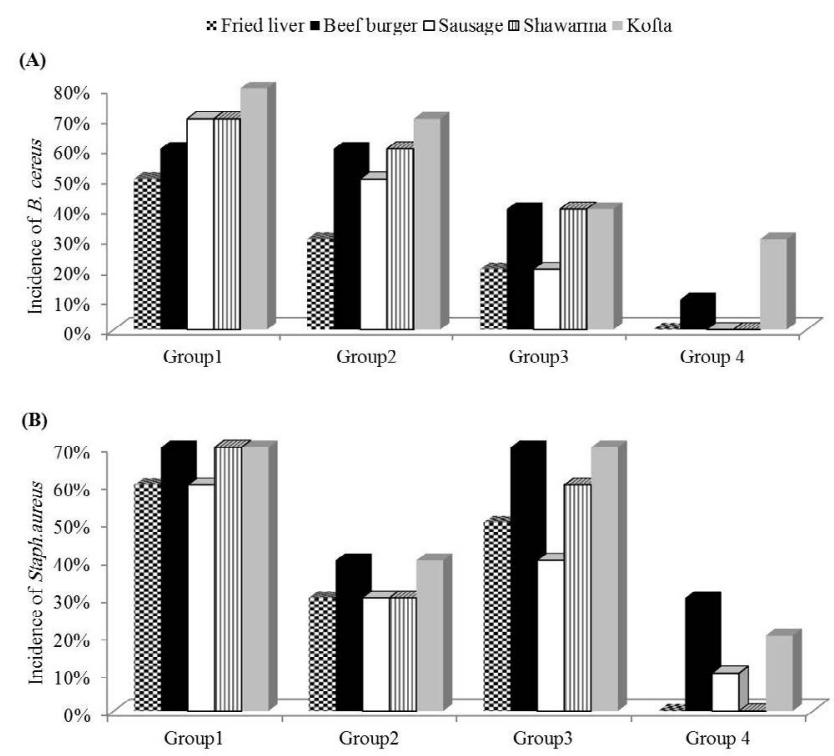

Figure 1: Percentage incidence of B.cereus (A) and S.aureus (B) in examined RTE meat sandwiches.

\section{DISCUSSION}

The APC is important in food microbiology as an indica- tor of the microbiological quality as well as a measure of sanitation used during the handling of a food (Ray, 2004). APC determines counts of the non-fastidious aerobic bacteria. In some foods, high APC may indicate poor quality. Higher bacterial numbers spoil the food faster and result in loss of quality. Food which appears normal may have high APC, indicating that the food is about to spoil. The recommended reference value for the APC of RTE sandwiches was indicated to be $<5 \mathrm{log}$ CFU/g (CFS, 2014). In this study, the mean APC of retail liver sandwich, beef burger sandwich, sausage sandwich, shawarma sandwich, kofta sandwich, vegetable salad and tahini sauce (group1) were exceeded $5 \log _{10} \mathrm{CFU} / \mathrm{g}$ (Table 1). Thus, indicate unacceptability of all sandwiches (group1). Vegetable salad considered as a source of contamination in sandwiches. In previous studies, Mensah et al. (2002) found APC of $6.3 \pm$ $0.78 \log _{10}$ CFU/g in salads retailed on the streets of Accra. As well, Christison et al. (2008) also reported high APC in salads. Vegetables had APC of 6.3-6.8 $\log _{10}$ CFU/ $g$ (Nyenje et al., 2012) in South Africa. Saddik et al. (1985) reported $6.69 \log _{10} \mathrm{CFU} / \mathrm{g}$ on vegetable samples in Egypt, while in Taiwan, it was reported as 3.30-8.64 $\log _{10}$ CFU/ $\mathrm{g}$ (Fang et al., 2003). Furthermore, Vural and Erkan (2008) found 6.43 to $7.63 \log 10$ CFU /g in Turkey.

Using of sodium hypocholrite at a concentration $50 \mathrm{ppm}$ in wash water used for salad ingredients for 10 minutes significantly decrease the APC load in processed salad from $7.32 \pm 1.29$ (group 1) to $4.26 \pm 0.41 \log 10 \mathrm{CFU} / \mathrm{g}$. Moreover, APC reduced in all sandwiches, which formulated after treatment of salad (group 2). Allende et al. (2009) studied the effect of sodium hypochlorite on APC for $1 \mathrm{~min}$, reported a 1-1.3 $\log \mathrm{CFU} / \mathrm{g}$ reduction. Gao et al. (2017) used chlorine in washing water of Coriandrum sativum for 15 minutes and reported APC reduced from 7 to $3.2 \log _{10} \mathrm{CFU} / \mathrm{g}$.

Tahini sauce usually prepared at the beginning of the day and used whole day in sandwiches without further heat treatment, thus could have bacterial growth. In current study, tahini sauce proved to have contamination with APC. A previous study (E1-Sherbeeny et al., 1985) reported slightly low count $\left(7.5 \log _{10} \mathrm{CFU} / \mathrm{g}\right)$ as compared to our current investigation $\left(8.04 \pm 1.12 \log _{10} \mathrm{CFU} / \mathrm{g}\right)$. Application through heating at $80{ }^{\circ} \mathrm{C}$ followed by rapid cooling, then keeping in refrigerator at $4^{\circ} \mathrm{C}$ significantly decrease $(p<0.05)$ APC in tahini sauce and all examined RTE sandwiches (group 3). Using of suitable heat treatments such as pasteurization reduces the levels of vegetative microorganisms in foods in addition to keeping refrigerated minimize post-process contamination.

Neither treatment of vegetable salad (group 2) nor tahini sauce (group 3) have ability to introduce the sandwiches 
to the acceptable level below $5 \log _{10} \mathrm{CFU} / \mathrm{g}$. Application of both treatments (group 4) have a highly significant decrease in APC. This emphasizes the capacity of additives as a clear source of contamination with APC. Thus, it is important to control the initial level of ingredients contamination, which used to prepare RTE sandwiches.

The presented data in Figure1 showed that Bacillus cereus detected by examining sandwiches with percentages of $50 \%, 60 \%, 70 \%, 70 \%$ and $80 \%$, respectively in liver, beef burger, sausage, shawarma and kofta (group 1). Schlegelova et al. (2003) found $28 \%$ of meat samples positive for B. cereus. Willayat et al. (2007) and Das et al. (2009) found $23.5 \%$ and $36.7 \%$ contamination level of B. cereus, respectively. This variation might be because hygienic practices followed in different localities in meat shops and restaurants.

In this study, the incidence of B.cereus was reduced after treatment of salad (group 2) to $30 \%, 60 \%, 50 \%, 60 \%$ and $70 \%$. Meanwhile, it became 20\%, 40\%, 20\%, 40\% and 40\% in liver, beef burger, sausage, shawarma and kofta sandwiches, respectively in tahini sauce treated group. Moreover, both treatments of vegetable salad and tahini sauce reduced B.cereus incidence to undetectable levels in liver, sausage, and shawarma (group 4). The counts of B.cereus in untreated (group1) were nearly similar (0.69 to $4.8 \mathrm{log}$ $\left.{ }_{10} \mathrm{CFU} / \mathrm{g}\right)$ and $\left(2-3.2 \log _{10} \mathrm{CFU} / \mathrm{g}\right)$ detected in Turkey by Güven et al. (2006) and Büyükyörük et al. (2014), respectively. There were no significant differences between the vegetable salad treated (group2) and untreated (group 1). This declared that vegetable salad not the common source of B.cereus. Meanwhile, significant decrease $(p<0.05)$ in count of B.cereus observed in tahini sauce treated (group 3 ). This finding proved that the source of $B$. cereus was tahini sauce due to multiplication of these organisms in the food when stored for extended times at temperatures above $8^{\circ} \mathrm{C}$. Application of both treatments (group 4) completely inhibit the presence of B.cereus in liver, sausage and shawerma, meanwhile detected in beef burger and kofta due to the spices included in meat product. These findings coincide with Little et al. (2003) who detected B. cereus in $33.3 \%$ of spice and spice ingredients, contained more than $4 \log _{10} \mathrm{CFU} / \mathrm{g}$.

The potential dangers from long-term storage and inappropriate temperature controls need to be emphasized given the requirement for B.cereus to grow in sufficient numbers to produce a toxin to cause food poisoning (Berthold-Pluta et al., 2015). Application of heat treatments during manufacturing of tahini sauce, followed by rapid cooling absolutely inactivate vegetative cells of B.cereus. However, the spores can survive this treatment and cause, after subsequent germination, food intoxication.
S.aureus and their association with foodborne intoxication has been a global public health concern. In the present study, S.aureus detected up to $70 \%$ of collected RTE sandwiches have clearly demonstrated that RTE sandwiches are contaminated either through meat samples or at different stages of preparation (Todd et al., 2007). A lower prevalence of S.aureus (8.3\%) was reported in sandwiches collected from Jordon (Nimri et al., 2014). In a study conducted on commonly consumed fast foods in Riyadh, Saudi Arabia, S.aureus detected in $44 \%$ and $18 \%$ of shawarma and burger, respectively (Al-Shabib et al., 2017).

Therefore, it can be assumed that RTE sandwiches are susceptible towards S.aureus contamination. The presence of $S$. aureus in the food samples tested in this study indicates improper handling and possible cross-contamination (Preedy, 2005). This microorganism not only plays an important role in foodborne diseases in the United States but in Taiwan as well S.aureus is the second most commonly found foodborne pathogen (Fang et al., 2003).

Dipping of green salad components in chlorine at a concentration of $50 \mathrm{ppm}$ for 10 minutes reduced S.aureus count to $<2 \log _{10} \mathrm{CFU} / \mathrm{g}$ of examined vegetable salad, moreover significant reduction in S.aureus count for examined liver, sausage and shawarma sandwiches (group 2). The effect of chlorine previously studied in Korea on lettuce at a concentration $50 \mathrm{ppm}$, which result in reduction in $S$. aureus count from 3.89 to $1.63 \log 10 \mathrm{CFU} / \mathrm{g}$ (Lee et al., 2009).

Using of essential garlic oil at concentration $1 \%$ reduced S.aureus count from $4.92 \pm 0.26 \mathrm{CFUlog}_{10} / \mathrm{g}$ to $<2$ in tahini sauce samples. Furthermore, S.aureus count significantly reduced in all examined sandwiches (group 3). The sensitivity of S. aureus was extensively studied. Kyung et al. (2002) reported that allicin of garlic essential oil showed strong antibacterial activity against $S$. aureus. The activity of garlic improved with in temperature up to $80^{\circ} \mathrm{C}$ (Roy et al., 2006). Both treatment of vegetable salads and tahini sauce reduce S.aureus counts significantly (group 4), thus declared that contamination level of RTE sandwiches need to be controlled in order to protect the consumer health.

\section{CONCLUSION}

Using chlorine in washing water of vegetables before preparing the vegetable salad and the addition of garlic oil to tahini sauce reduced the bacterial counts. Using this treated vegetable salad and tahini sauce in meat sandwiches has resulted in a significantly low bacterial count thus increase the safety margin for the consumer. 


\section{AUTHOR CONTRIBUTION}

All authors contributed equally.

\section{CONFLICT OF INTEREST}

None of the authors has any conflict of interest to declare.

\section{REFERENCES}

- Allende A, McEvoy J, Tao Y, Luo Y (2009). Antimicrobial effect of acidified sodium chlorite, sodium chlorite, sodium hypochlorite, and citric acid on Escherichia coli O157: H7 and natural microflora of fresh-cut cilantro. Food Control. 20(3): 230-234. https://doi.org/10.1016/j. foodcont.2008.05.009

-Al-Shabib NA, Husain FM, Ahmad I, Baig MH (2017). Eugenol inhibits quorum sensing and biofilm of toxigenic MRSA strains isolated from food handlers employed in Saudi Arabia. Biotechnol. Biotechnol. Equip. 31(2):387396. https://doi.org/10.1080/13102818.2017.1281761

-Berthold-Pluta A, Pluta A, Garbowska M (2015). The effect of selected factors on the survival of Bacillus cereus in the human gastrointestinal tract. Microb. Pathog. 82: 7-14. https://doi.org/10.1016/j.micpath.2015.03.015

•Büyükyörük S, Beyaz D, Göksoy Eö, Kök F, Kocak P (2014). Microbiological evaluation of ready-to-eat sandwiches served near hospitals and schools. Academic Journal of Ankara Üniversitesi Veteriner Fakultesi Dergisi. 61(3): 193198. https://doi.org/10.1501/Vetfak_0000002628

- Cavallito CJ, JS Buck, CM Suter (1944). Allicin, the antibacterial principle of Allium sativum. II: determination of the chemical structure. J. Am. Chem. Soc., 66:1952-1954. https://doi.org/10.1021/ja01239a049

-Center for Food Safety “CFS"(2014).Microbiological guidelines for food (Ready-to-eat food in general and specific food items). Risk Assessment Section, Food and Environmental Hygiene Department. The Expert Committee on Food Safety, 43/F, Queensway Government Offices. 66 Queensway, Hong Kong).

-Chand B (2013). Antibacterial effect of garlic (Allium sativum) and ginger (Zingiber officinale) against Staphylococcus aureus, Salmonella typhi, Escherichia coli and Bacillus cereus. J. Microbiol. Biotechnol. Food Sci. 2(4): 2481.

-Christison CA, Lindsay D, von Holya A (2008).Microbiological survey of ready-to-eat foods and associated preparation surfaces in retail delicatessens, Johannesburg, South Africa. J. Food Control. 19: 727-733. https://doi.org/10.1016/j. foodcont.2007.07.004

- Cowan ST, Steel KA (1974). Manual for the Identification of Medical Bacteria. Front Cover. Cowan. John Steel, Steel. Cambridge University Press.

-Das S, Surendran PK, Thampuran N (2009). PCR-based detection of enterotoxigenic isolates of Bacillus cereus from tropical seafood. Indian J. Med. Res. 129:316-320.

-El-Sherbeeny MR, Saddik, M F, Bryan FL (1985). Microbiological profiles of foods served by street vendors in Egypt. Int. J. Food Microbiol. 2(6):355-364. https://doi. org/10.1016/0168-1605(85)90026-1

-Fang TJ, Wei QK, Liao CW, Hung MJ, Wang TH (2003). Microbiological quality of $18 \mathrm{C}$ ready-to-eat food products sold in Taiwan. Int. J. Food Microbiol. 80(3): 241-250. https://doi.org/10.1016/S0168-1605(02)00172-1

-FDA (2000). Food Code Recommendation of the United States Public Health Service. Food and Drug Administration, Washington, DC., USA.

- Feldman D, Ganon J, Hoffman R, Simpson J (2003). The solution for data analysis and presentation graphics. $2^{\text {nd }} \mathrm{Ed}$., Abacus Lancripts, Inc., Berkeley, USA.

- Gao H, Fang X, Li Y, Chen H, Zhao QF, Jin TZ (2017). Effect of alternatives to chlorine washing for sanitizing fresh coriander. Annu Rev. Food Sci. Technol. 54(1): 260-266. https://doi.org/10.1007/s13197-016-2458-7

-Ghosh M, Wahi S, Kumar M, Ganguli A (2007). Prevalence of enterotoxigenic Staphylococcus aureus and Shigella spp. in some raw street vended Indian foods. Int. J. Environ. Health Res. 17: 151-156. https://doi. org/10.1080/09603120701219204

- Griffiths MW, Schraft H (2017). Bacillus cereus food poisoning. In Foodborne diseases (pp. 395-405). Academic Press. https://doi.org/10.1016/B978-0-12-385007-2.00020-6

-Gueven K, Mutlu MB, Avci O (2006). Incidence and characterization of Bacillus cereus in meat and meat products consumed in Turkey. J. Food Saf. 26(1): 30-40. https://doi. org/10.1111/j.1745-4565.2005.00031.x

- Hussein MA, Eldaly EA, Seadawy HG, El-Nagar EF (2018). Virulence and antimicrobial resistance genes of Escherichia coli in ready to eat sandwiches in sharkia governorate. Slovenian Vet. Res. 55: 383-392.

-ISO 4833-1 (2013). Microbiology of the food chain Horizontal method for the enumeration of microorganisms - Part 1: Colony count at $30^{\circ} \mathrm{C}$ by the pour plate technique.

-ISO 6887-2 (2003). Microbiology of food and animal feeding stuffs - Preparation of test samples, initial suspension and decimal dilutions for microbiological examination - Part 1-3: Specific rules $f$ or the preparation of meat and meat products.

-ISO 6888-1 (1999). Microbiology of food and animal feeding stuffs -- Horizontal method for the enumeration of coagulase-positive Staphylococci (Staphylococcus aureus and other species) -- Part 1: Technique using Baird-Parker agar medium.

-ISO 7932 (2004). Microbiology of food and animal feeding stuffs -- Horizontal method for the enumeration of presumptive Bacillus cereus -- Colony-count technique at $30^{\circ} \mathrm{C}$.

-Jessberger, N., Dietrich, R., Granum, P.E. and Märtlbauer, E., (2020). The Bacillus cereus food infection as multifactorial process. Toxins. 12(11): 701. https://doi.org/10.3390/ toxins12110701

• Kim HJ, Kim D, Kim HJ, Song SO, Song YH, Jang A (2018). Evaluation of the microbiological status of raw beef in Korea: Considering the suitability of aerobic plate count guidelines. Korean J. Food Sci. Anim. Res. 38(1): 43.

-Kyung KH, Kim MH, Park MS, Kim YS (2002). Alliinaseindependent inhibition of Staphylococcus aureus B33 by heated garlic. J. Food Saf. 67(2): 780-785. https://doi. org/10.1111/j.1365-2621.2002.tb10676.x

-Lee SY, Baek SY (2008). Effect of chemical sanitizer combined with modified atmosphere packaging on inhibiting Escherichia coli O157:H7 in commercial spinach. Food Microbiol. 25:582-587. https://doi.org/10.1016/j. fm.2008.02.003

-Lee YS, Jo SH, Cho SD, Kim GH, Kim YM, Lee DH, 
Ha SD (2009). Effects of chlorine concentrations and washing conditions on the reduction of microbiological contamination in lettuce. Korean Soc. Appl. Biol. Chem. 52(3): 270-274. https://doi.org/10.3839/jksabc.2009.048

- Little CL, Omotoye R, Mitchell RT (2003). The microbiological quality of ready-to-eat foods with added spices. Int. J. Environ. Health Res.13(1): 31-42. https://doi. org/10.1080/0960312021000063331

-Mensah P, Yeboah-Manu D, Owusu-Darko K, Ablordey A (2002). Street foods in Accra, Ghana: How safe are they. WHO Bull. 80: 546-554.

- Nimri L, AL-Dahab FA, Batchoun R. (2014). Foodborne bacterial pathogens recovered from contaminated shawarma meat in northern Jordan. J. Infect. Dev Ctries, 8(11): 14071414. https://doi.org/10.3855/jidc.4368

- Nyenje ME, Odjadjare CE, Tanih NF, Green E, Ndip RN, (2012). Foodborne pathogens recovered from ready-toeat foods from roadside cafeterias and retail outlets in Alice, Eastern Cape Province, South Africa: public health implications. Int. J Environ. Res. Pub. Health. 9(8): 26082619. https://doi.org/10.3390/ijerph9082608

- Preedy VR (2005). Reviews in Food and Nutrition Toxicity. 3. CRC Press. https://doi.org/10.1201/9781420037531

- Ray B (2004). Fundamental Food Microbiology. $3^{\text {rd }}$. edition. CRC Press. https://doi.org/10.1201/b12450

- Rhodehamel EJ, Harmon SM (1998). Bacteriological analytical manual online, $8^{\text {th }}$ ed. Revision. Chapter 14 [monograph on the internet]. U.S. Food and Drug Administration; 2001. Available from http://www.cfsan.fda.gov/ ebam/bam-14. html\#author.

- Roy J Shakaya DM, Callery PS, Thomas JG (2006). Chemical constituents and antimicrbila activity of a traditional herbal medicine containing garlic and black cumin. Afr. J. Trad., CAM 3 (20): 1-7. https://doi.org/10.4314/ajtcam. v3i2.31151

- Saddik MF, El-Sherbeeny MR, Bryan FL (1985). Microbiological profiles of Egyptian raw vegetables and salads. J. Food Protect. 48: 883-886. https://doi. org/10.4315/0362-028X-48.10.883

-Schlegelova J, Brychta J, Klimova, Napravnikova E, Babak V (2003). The prevalence of and resistance to antimicrobial agents of Bacillus cereus isolates from foodstuffs. Vet. Med.-Czech 11:331-338. https://doi.org/10.17221/5787VETMED

- Tamarapu S, McKillip JL, Drake M (2001). Development of a multiplex Polymerase chain reaction assay for detection and differentation of Staphylococcus aureus in dairy products. J. Food Protect. 64: 664-668. https://doi.org/10.4315/0362028X-64.5.664

- Todd EC,GreiJD,Bartleson CA,Michaels BS (2007). Outbreaks where food workers have been implicated in the spread of foodborne disease. Part 3.Factors contributing to outbreaks and description of outbreak categories. J. Food Protect. 70: 2199-2217. https://doi.org/10.4315/0362-028X-70.9.2199

-Vural A, Erkan ME (2008). Investigation of microbial quality of some leafy green vegetables in Turkey. J. Food Technol. 6: 285-288.

-Willayat MM, Sheikh GN, Misgar GR (2007). Prevalence of Bacillus cereus biotypes in raw and cooked mutton. J. Vet. Pub. Health.5(2) : 123-125.

-Zhang S, Iandolo J, Stewart C (1998). The enterotoxin D plasmid of Staphylococcus aureus encodes a second enterotoxin determinant (sej). FEMS Microbiol. Lett. 168: 227-233. https://doi.org/10.1111/j.1574-6968.1998.tb13278.x 